\title{
Sobre os restos: Infância berlinense por volta de 1900
}

\section{Sabrina Sedlmayer - UFMG}

Resumo: Procura-se discutir, neste trabalho, o apego ao fragmentário e ao inacabado em textos que se assumem como "antiautobiografias" ou "autobiografias negativas," e que se posicionam contra o tradicional gesto de recuperação de uma vida particular através de uma narrativa memorialística linear. Tomando como ponto de partida para reflexão a obra Infância berlinense por volta de 1900, em que Benjamin dispõe de imagens topológicas da cidade natal e de seletos objetos, - restos da memória -, problematiza-se em que medida o desenho de um sujeito histórico e coletivo é estrategicamente afirmado nos quarenta e um fragmentos em detrimento de uma categorização do sujeito como sinônimo de individualidade.

Palavras-chave: subjetividade, memória, fragmento

\section{I - Varandas: autorretrato}

Numa conversa com Brecht, em oito de junho de 1931, Benjamin propõe ao amigo que dialeticamente discutam um dos seus temas favoritos: o fato de habitar. Brecht inicia argumentando que habitar seria o que dá medidas, o que configura o seu entorno, de forma ordenada e adequada; Benjamin, em contrapartida, defende a posição de quem, em qualquer lugar do mundo, se sente só como um hóspede. Dessas duas polaridades extremas, o habitante que possui o máximo de hábitos e o habitante que possui o mínimo de hábitos, Benjamin retém, para a sua posterior escrita diarística, quatro modos de habitar, sendo um deles particularmente importante para o tema que proponho desenvolver neste texto, laconicamente localizado numa frase de Nietzsche: "me encantam os hábitos breves".

Se breve pode ser relacionado, num primeiro momento, à recusa dos hábitos que configuram o habitante, que fazem com que o morador estabeleça com os objetos uma relação acumulativa ao ponto de se tornar parte do cenário, também deve estar vinculado à escrita breve, à particular experiência empreendida por aqueles que acirradamente se opõem a ideia de linearidade e continuidade histórica, aqui agrupada pelos nomes de Nietzsche, Brecht e Benjamin, e que defendem, seja pelo uso do fragmento ou do aforismo, da cesura ou da interrupção, certa economia e uso das palavras, determinadas potencialidades reativas contidas na utilização da forma fragmentária.

Dois anos após ter refletido sobre os modos agregadores e desagregadores do verbo alemão Das mitahmende Wohmen ${ }^{l}$ - que literalmente quer dizer o "habitar que dá medidas", e que Brecht, na conversa citada, criou o verbo mitahmen, alterando o de acordo para o sufixo com, justamente para criticar a subserviência de quem adota os 
hábitos para se ajustar ao salão burguês -, Benjamin escreve "Experiência e pobreza" (1933), em que retoma Brecht e alguns pontos da discussão para defender a atitude oposta ao hábito, a ruptura.

Este Benjamin entusiasmado com a cultura arquitetônica vanguardista e os seus materiais fala então da não fixidez - do duro e liso vidro -, em oposição à aveludada casa burguesa onde não há espaço "em que seu habitante não tivesse deixado seus vestígios" (Benjamin, 1994, p. 117). Brecht e Benjamin estão aqui unidos na crítica daquele que mora calcado na semelhança, preso a modelos e referências, e diz amen aos temas e motivos alheios. O neologismo brechtiano propõe, assim, um modelo movido pelo viver com (mit), e a fala de Nietzsche vai totalmente de encontro ao antievolucionismo, à instabilidade e à crise, a descontinuidade histórica.

$\mathrm{Na}$ terceira referência aos hábitos de curta duração, especificamente no fragmento nove de Parque central, ao discorrer sobre o fato de o eterno retorno transformar o evento histórico em mercadoria de massa, mas ao mesmo tempo mostrar "o rastro das circunstâncias econômicas às quais deve sua súbita atualidade” (Benjamin, 1989, p. 156), Benjamin cita novamente Nietzsche para confirmar como nas vanguardas o hábito "renunciava alguns dos seus direitos". Agrega, então, Baudelaire, como o exemplo daquele que foi incapaz de "desenvolver hábitos estáveis durante a vida inteira" (Benjamin, 1989, p. 157).

O poeta que mudou de endereço mais de dez vezes em um ano, e que fez das ruas de Paris o interior da sua casa, é também aquele que, segundo Giorgio Agamben (2007), diante da intromissão da mercadoria, "respondeu a essa intromissão, transformando em mercadoria e em fetiche a própria obra de arte”. Se a importância ímpar de Baudelaire se deve não apenas pelo fato de não ter reproduzido a cesura entre valor de troca e valor de uso, mas de criar uma mercadoria na qual a forma de valor se identificasse totalmente com o valor de uso, na qual a fetichização anulasse a realidade da mercadoria como tal, também auxiliou Benjamin a se aprofundar no potencial de estranhamento que carregam os objetos quando perdem a sua aura, a sua autoridade. A poesia baudelairiana mostrou, então, a Benjamin como a revolução é capaz de "desencantar a cidade" (Benjamin, 1989, p. 192). Nesse sentido, a experiência de choque nasce e se desenvolve com o declínio da aura, e opõe-se, dessa forma, à experiência autêntica, logo, ao hábito da tradição.

É nesse sentido que no ensaio "A obra de arte na era de sua reprodutibilidade técnica" Benjamin descreve como o hábito amortece a percepção, e como as tarefas impostas ao aparelho perceptivo do homem são insolúveis quando atreladas apenas à contemplação. Demonstra como até mesmo os distraídos podem habituar-se. Utiliza, então, o cinema como exemplo de que o homem pode aprender a se habituar no tempo do descontínuo. Os inúmeros fotogramas, as imagens vertiginosas, compostos pelo trabalho da montagem, ensinariam a técnica, a educação para uma nova percepção, para um novo tempo.

Mas vale reter, aqui, como essa nova percepção está intrinsecamente ligada à noção de ruptura, além, é claro, do declínio necessário da aura. E a construção literária deveria também subverter as formas tradicionais do gênero. A noção de inacabamento, além de ser característica de toda reflexão benjaminiana, seja através do uso sistemático da citação, da montagem, na qual a Obra das Passagens é o exemplo mais modelar, é também a realização do pensamento pela forma breve. Muito mais que uma questão de estilo, preocupa-o justamente a tarefa da transmissão, da rememoração (Eigedenken). E a rememoração, diferentemente da memória, transfigura e obriga tudo a ser reconstruído, ressignificado, como bem pontuado no célebre texto "A imagem de Proust": "o 
importante para o autor que rememora, não é o que ele viveu, mas o tecido de sua rememoração, o trabalho de Penélope da reminiscência. Ou seria preferível falar do trabalho de Penélope do esquecimento"? (Benjamin, 1994, p. 37).

Para Benjamin, Proust fez do século XIX um século para memorialistas. Apesar de pontuar a "fisiologia da tagarelice" realizada pelo memorialista francês (Benjamin, p. 1994, 41), afirma, em Infância berlinense, que quer realizar outro tipo de autobiografia, distinto da empreitada proustiana. Deseja transgredir os limites ditados pelo gênero. Para Willi Bolle (2000, p. 314), na "trilogia berlinense" (Grosstadt Berlim, Crônica berlinense e Infância berlinense), Benjamin realizou o tableau urbano e conciliou a ênfase na histórica coletiva com a escrita autobiográfica.

Em outra obra, intitulada Escritos autobiográficos, publicada bem posteriormente a sua morte, que traz textos coligidos no período de 1906 a 1940, Benjamin reiteradamente reflete sobre o estilo, a escrita, a forma, sobre os gêneros. Nesses textos de natureza variada - notas, diários, apontamentos -, encontra-se uma quantidade considerável de comentários sobre a linguagem e a escrita da memória. O pronome "eu" é utilizado sem parcimônia. Sempre em forma breve, sem destinatários, os apontamentos falam de vivências relacionadas a algum motivo biográfico.

Evidencia-se, assim, nesses textos, o uso particular do pronome "eu". Segundo Concha Martorell, a compilação responde adequadamente aos quatros motivos que Roland Barthes (apud Martorell, 1996, p. 12) atribui a justificativa de se escrever um diário:

1) poético: compor um texto permeado da individualidade de escritura, de estilo; 2) histórico: oferecer, dia após dia, os traços de uma época; 3) utópico: constituir o autor como objeto de desejo, o leitor pode querer - de um escritor que lhe interesse - sua intimidade, gostos, humores, escrúpulos; 4) amoroso: converter o diário em um conjunto de frases, não belas, mas senão frases justas.

Mas o que parece estar em jogo é justamente o gesto de procura de uma escrita que não esteja pronta, dada pela tradição, seja pelos gêneros literários ou filosóficos. Esse tópos se dilata e se espraia também para a leitura da experiência de escrita de outros autores, como a literatura de Hemingway e de Kafka. Numa curiosa passagem, Benjamin (1996, p. 149) deduz que "o mau escritor é o escritor que sempre diz mais do que pensa", ou aquele que cultiva a clareza e a sensibilidade como qualidades de escrita:

A base de todas as questões de estilo é que não existe em absoluto esta: dizer o que se pensa. Pois o dizer não é somente uma expressão, e sim toda uma realização do pensar que o submete às mais profundas modificações, exatamente igual que o caminhar até uma meta não é somente a expressão de um desejo de alcançar senão sua realização, e expõe a este desejo as mais profundas modificações. (p. 149)

Através da citação anterior se percebe como a forma de dizer não é expressão, e como a forma sucinta, cara ao romantismo alemão, particularmente desenvolvido no conceito de Witz, relaciona-se justamente a densidade e a rapidez. A prática fragmentária, no final do século XVIII, almejava ser tal como um relâmpago elétrico e iluminado. Imobilizavase a história, evitava-se o desenvolvimento em extensão ou o desenrolar de um raciocínio, e, como uma espécie de microcosmo, apresentava-se uma ideia. 
Mas, no "pensamento itinerante" de Benjamin, expressão cunhada por Blanchot para descrever a eleição da forma fragmentária por Nietzsche, a realização da obra não busca a totalidade, como nos românticos de Iena. Nesse tipo especial de escrita que pratica Benjamin, como pontua o crítico francês, há uma exigência de descontinuidade e de inacabamento: "a interrupção é necessária em toda a seqüência de palavras; a intermitência torna possível o devir; a descontinuidade assegura a continuidade do pensamento" (Blanchot, 2001, p. 132). O intervalo, assim, é que permite a alternância do diálogo. Nesse sentido, encontramos também referência aos surrealistas e a premissa da necessidade do despertar, a importância dos sonhos e, claro, o antissubjetivismo. Em Benjamin, vale negritar, a questão do gênero encontra-se completamente associada à questão do sujeito, logo, a enunciação.

Assim pode-se pensar, com Gagnebin, que se corre o perigo, numa rasa recepção da sua obra, de se sublinhar em demasia apenas o inacabamento e as imagens do pensamento como formulações luminosas, carregadas de poeticidade, e se esquecer do denso e rigoroso trabalho reflexivo e crítico da obra, e a eleição da escrita fragmentária como espécie de exigência da obra que preza a descontinuidade e a composição heterogênea:

Como se esses textos - fragmentos, imagens, aforismos - favorecessem certa preguiça do pensamento, em nome de uma subjetividade e de uma sensibilidade tão imediatas quanto triviais, em vez de aguçarem a exigência, que sua própria forma no entanto coloca, de uma renovação do pensamento, em direção a uma diferenciação e a uma flexibilidade maiores e, nesse sentido, sim, de uma sensibilidade fiel à pluralidade do real. (Gagnebin, 1999, p. 61-62)

A forma do pensamento convida, assim, a renovação do pensamento, e o gesto da reflexão a profundas modificações e ressignificações. A "arquitetura interna" do hábito breve, da escrita breve, difere-se da forma dada tradicionalmente pelo tratado, por exemplo, como Benjamin (1987, p. 35) descreve em Rua de mão única:

O tratado é uma forma arábica. Seu exterior é indiferenciado e não chama a atenção, correspondendo à fachada de construções árabes, cuja articulação só começa no vestíbulo. Assim também a estrutura articulada do tratado não é perceptível do exterior e só se abre pelo interior. Se os capítulos o formam, não são sobrescritos verbalmente, mas designados por cifras. A superfície de suas deliberações não é pictoricamente vivificada, mas antes coberta com as redes de ornamento que se vai enrodilhando sem ruptura. Na densidade ornamental dessa exposição desaparece a diferença entre desenvolvimentos temáticos e excursivos.

O fragmento possui uma imagem pictórica exterior. É rodeado de lacunas, brancos, intervalos, diferentemente do tratado, que é todo articulado. Para os românticos alemães, a forma mais acabada do fragmento seria a do ouriço. Mas, como veremos a seguir, se fosse possível encontrar uma arquitetura interna capaz de encenar uma imagem da forma da escrita do eu, em Benjamin, essa forma seria a de uma varanda. Construção que, paradoxalmente, acolhe, mas ao mesmo tempo só permite permanências breves. 


\section{II - Para o eu não ser vendido}

Nas conhecidas "Palavras prévias" de Berliner Chronik, Benjamin alerta ao seu leitor que em todos os seus escritos, com exceção dos textos epistolares, foi fiel à regra de não se utilizar o pronome "eu". Esse princípio, intrinsecamente relacionado aos apontamentos norteadores do livro, um encontro de uma criança com a cidade de Berlim tempos depois de ter sido seu habitante, não só aponta para uma criteriosa vigilância, mas também para uma rigorosa exigência: que a palavra "eu" apenas represente o trabalho misterioso da memória, as infinitas interpolações naquilo que já se foi, e se abra para o avesso do ensimesmamento, a experiência do choque.

Se eu e sujeito, nessa referida passagem, não são termos intercambiáveis, nem muito menos idênticos, e passam a "estabelecer um sentido de representação no sentido político do termo (Vertretung e não Vorstellung)" como agudamente pontua Gagnebin (2006, p. 74), também demonstram certo desconforto em relação ao tradicional gênero autobiográfico.

Tal como o termo vestígio (spuren), o pronome pessoal em primeira pessoa aparece em Infância berlinense por volta de 1900 de forma paradoxal. É utilizado, é presente, mas ao mesmo tempo é atravessado por livros, escrivaninhas, armários, jogos, pontes, borboletas, telefone, imagens da infância que, segundo o autor, antecipariam experiências históricas posteriores, que fugazmente desaparece. Benjamin parece querer experimentar e levar adiante a função do pronome, mas, vigilantemente, evitar a sua personalização.

Numa carta de 1933, endereçada a Scholem, Benjamin afirma que o melhor retrato que fez de si mesmo nesse livro foi no fragmento intitulado "Varandas". Vale lembrar um pequeno excerto desse texto para embasar como, na recuperação das imagens que, no exílio, despertavam a nostalgia da infância, traços biográficos "que se revelam mais na continuidade do que na profundidade da experiência" (Benjamin, 2004, p. 74) não recuam tão completamente para um plano de fundo como Benjamin afirma. Ciente das exortações de Proust sobre a irreversibilidade do tempo passado, e mesmo tendo uma postura seletiva e cautelosa no sentido de evitar o casual e o biográfico a favor do necessário e social, há rastros de uma singularidade, de um eu, que são reiteradamente apresentados:

As varandas mudaram menos desde a minha infância do que as outras divisões. Mas não é só por isso que as sinto mais próximas. É antes pelo consolo que a sua inabitabilidade traz a quem, por assim dizer, já não consegue viver em lugar nenhum. Nelas, a habitação do berlinense encontra a sua fronteira. Berlim - o próprio deus da cidade - começa aí. Está aí de forma tão presente que nada que seja transitório se pode afirmar ao seu lado. Sob a sua proteção, o lugar e o tempo encontram-se a si mesmos, e um a outro. Ambos se deitam aí a seus pés. Mas a criança que um dia se aliou a eles instala-se, confundindo-se com o seu grupo, na sua varanda como num mausoléu que há muito tempo lhe estava destinado. (Benjamin, 2004, p. 76)

A palavra varanda, no texto original de Benjamin utilizada em italiano, no plural, loggien, refere-se a galerias sustentadas por colunas, espaço de transição, compartimento aberto, nem totalmente exterior, nem totalmente interior. Espécie de umbral, é também intervalo, lugar intermediário caro a Benjamin em quase toda extensão de sua obra. Um hiato, poder-se-ia supor, entre o que seria relativo a si mesmo e o que pertenceria a outro. 
Benjamin preza as galerias, as escadas, os corredores, onde a errância se dá. Mais espaço que tempo. Essa tênue fronteira, ou delicada oscilação, entre o que é o eu e o que é o objeto é um dos elementos mais importantes da escrita do eu em Benjamin. Poderíamos acrescentar que se trata de um gesto (negar o sujeito individual e reafirmar o sujeito coletivo) radicalmente diverso das formas expressivas que o eu vem assumindo nos últimos 20 anos. As manifestações literárias apresentadas nas primeiras décadas do século passado e posteriormente em algumas obras que tematizavam o que se convencionou a denominar genericamente de crise do sujeito parecem não prevalecer em tempos de hiperpresença dos meios de comunicação. Segundo o tradutor português de Benjamin, João Barrento, a homogeneização causada pela globalização, entre outros incisivos fatores, causou, na contemporaneidade, um "princípio eudemonista dominante". Blogs, twitter, orkut, facebook trazem uma outra forma de se contar, com recursos tecnicamente inovadores, narrativas do e sobre o eu. Presenciamos, assim, uma "guinada subjetiva", como cunha Beatriz Sarlo (2005, p. 50): "proliferam as narrações chamadas não-ficcionais (tanto no jornalismo quanto na etnografia social e na literatura): testemunhos, histórias de vida, entrevistas, autobiografias, lembranças e memórias, relatos identitários".

Deve-se salientar como a importância da subjetivação, o uso do pronome "eu", demonstrado por Bakhtin, para citar apenas um dos teóricos relevantes sobre a questão de quem fala no romance, é muito mais do que um objeto temático. É sabido que o que chamamos de autobiografia hoje não se deu sempre dessa forma. No Iluminismo, os limites entre ficção e não ficção já se torna turvo: quem é Jean-Jacques é quem é Rousseau?

"Dou começo a uma empresa que não há exemplos e cuja execução não terá imitadores", diz o autor das Confissões no século XVIII. Benjamin, leitor de Rousseau e dos Diários, de Gide, experimenta em Infância berlinense o que, agudamente, já havia dito anteriormente: no século XIX assiste-se ao declínio de um caráter social baseado na sinceridade.

Tema desenvolvido por Carla Milani Damião, cujo estudo persegue a possibilidade de se narrar em tempo de crise e o modo como a teoria da experiência sustenta a reflexão benjaminiana sobre o objeto literário, a autora defende que na narrativa de si mesmo, na autobiografia e no diário, Benjamin emprega o gênero de maneira negativa e transgressora, "de modo a revelar quase a negação do si-mesmo" (Damião, 2006, p. 21).

O crítico literário espanhol José María Pozuelo Yvancos parece compartilhar, em parte, a posição de Damião no que se refere ao fato de a crise do gênero autobiográfico ter raízes profundas na filosofia. Apesar de não citar Benjamin em seu livro De la autobiografia (2006), e sim Nietzsche - como autor opositor das formas tradicionais de se contar a vida e inaugurar em Ecce homo um lugar para quem fala prenhe de máscara, embuste, ironia e jogo -, recupera a antiga discussão "a autobiografia é lida como ficção?" para adicionar novas referências teóricas capazes de problematizar o estatuto pragmático da definição do gênero. Para Yvancos, a enorme variedade e formas que adota o gênero (e a questão de o gênero autobiográfico abrigar vários estilos dentro dele mesmo) e a vinculação à verdade da natureza do narrado com um pretenso discurso autentificador, fazem com que duas correntes críticas se contraponham num jogo estéril e dicotômico: uma que pensa que toda narração de um eu é uma forma de ficcionalização, inerente ao estatuto retórico da identidade e que vê disseminado o autobiográfico em todo tipo de literatura (poderíamos agrupar, nesse grupo, os nomes de Paul de Man, Barthes, Derrida e outros "desconstrutivistas" que procuram em Nietzsche, Goethe, Proust e 
Valéry o embasamento para a defesa de que os domínios literários, filosóficos e críticos são apenas distinguidos retoricamente); a segunda, a que resiste considerar a autobiografia como ficção e sublinha a importância histórica e documental das autobiografias (aqui, além do defensor do pacto, Lejeune, podemos também elencar Elisabeth Bruss).

Como se vê, as perspectivas teóricas são vistas pelo crítico espanhol como embate de diferentes territórios. Talvez fosse interessante observar que, ao invés de se pensar a autobiografia como um gênero de "fronteiras", devesse lembrar o que Benjamin (2006, p.535) efetivamente experimentou em sua obra: um pensamento não do limite, mas do limiar:

O limiar (Shwelle) deve ser rigorosamente diferenciado da fronteira (Grenze). O limiar é uma zona. Mudança, transição, fluxo estão contidos na palavra schwellen (inchar, entumescer), e a etimologia não deve negligenciar estes significados. Por outro lado, é necessário determinar o contexto tectônico e cerimonial imediato que deu à palavra o seu significado.

Infância berlinense poderia ser vista, assim, não como vontade de verdade, ou de construção de um sujeito colado a uma estrutura. Sem a fixidez que ilusoriamente a noção de identidade costuma oferecer, Benjamin é um pensador do limiar, das passagens, diferentemente da fronteira essencialista que tenta separar linguagem, discurso e gênero.

\section{III - O que resta}

Da longa, tortuosa e complexa narrativa editorial e filológica que constitui a história de como Berliner Cronik foi transformado em Infância berlinense, ${ }^{2}$ ou mesmo como possui afinidades com este último livro, é interessante recuperar como o posicionamento narrativo do memorialista, que conta as suas impressões sobre sua cidade natal, sofreu consideráveis alterações. Dependendo da versão, da ordenação e da seleção dos fragmentos, a primeira pessoa foi transformada em terceira, alterando, assim, não apenas o locus de enunciação das "anotações isentas de marcas demasiadamente individuais ou familiares", como mais fortemente a diminuição da perspectiva autobiográfica em função de uma intencionalidade documental e referencial.

Benjamin escreveu esse texto, como se sabe, em Ibiza, num exílio atormentado pela ideia de morte. Os fragmentos obedecem à disciplina do desvio, seu método de trabalho. $\mathrm{O}$ eu aparece nesses textos como um meio sem fim, segundo o precioso título de um livro de Agamben, um dos estudiosos da sua obra. Também com Agamben poderíamos supor que o sujeito é resto. Há, nessa afirmação, um núcleo teológico-messiânico nunca negado por Benjamin (nem pelo pensador italiano contemporâneo). É dever da memória não esquecer o elo entre subjetividade e infância. É dever da memória, além de lembrar de livros, escrivaninhas, armários, talismã da mãe, bolhas de sabão, jardins, reconhecer, no presente, os vestígios do passado. Ir na pegada, no indício, no sinal, na esteira de um eu que já não mais se encontra ali, mas, no entanto, deixou rastro.

ABSTRACT: This paper seeks to discuss the attachment to the fragmentary and the unfinished in texts meant as "antiautobiographies" or 
"negative autobiographies" that stand against the traditional gesture of recovering a private life through a memorialistic linear narrative. Taking as starting point the work Berlin Childhood around 1900, in which Benjamin lays topological images of his home town and selected objects, -memory residues - we discuss to what extent the shape of a collective and historical subject is strategically stated in the fortyone fragments rather than in a categorization of the subject as synonym of individuality.

Keywords: subjectiviness; memory; fragment

\section{Referências Bibliográficas}

AGAMBEN, Giorgio. Estâncias, a palavra e o fantasma na cultura ocidental. Tradutor Selvino José Assmann, Belo Horizonte, 2007.

BARRENTO, João. “Comentário”. En: BENJAMIN, Walter, "Infância Berlinense: 1900 (versão de última mão)". En: Imagens do pensamento, Obras escolhidas de Walter Benjamin, edição e tradução de João Barrento, Assírio\& Alvim, Lisboa, 2004.

BARTHES, Roland. "Introducción”. En: MARTORELL, Concha Fernández, Walter Benjamin, escritos autobiográficos, Alianza Editorial, versión española de Teresa Rocha Barco, Madrid, 1996.

BENJAMIN, Walter, "Experiência e pobreza". En: Magia e técnica, arte e política: ensaios sobre literatura e história da cultura, Obras escolhidas. Tradutor Sérgio Paulo Rouanet; Brasiliense, São Paulo, 1994.

BENJAMIN, Walter, "Parque Central". En: Charles Baudelaire: um lírico no auge do capitalismo, Obras escolhidas III. Tradutor José Martins Barbosa, Hermerson Alves Baptista; Editora Brasiliense, São Paulo, 1989.

BENJAMIN, Walter, “A imagem de Proust”. En: Magia e técnica, arte e política: ensaios sobre literatura e história da cultura, Obras Escolhidas. Tradutor Sérgio Paulo Rouanet; Editora Brasiliense, São Paulo, 1994.

BENJAMIN, Walter, Escritos autobiográficos, Alianza Editorial, versión española de Teresa Rocha Barco, Madrid, 1996.

BENJAMIN, Walter, "Rua de mão única". En: Obras Escolhidas II, Tradução de Rubens Rodrigues Torres Filho e José Carlos Martins Barbosa, editora Brasiliense, 1987.

BENJAMIN, Walter, "Infância Berlinense: 1900 (versão de última mão)". En: Imagens do pensamento, Obras escolhidas de Walter Benjamin, edição e tradução de João Barrento, Assírio\& Alvim, Lisboa, 2004.

BENJAMIN, Walter, Passagens. Organização da edição brasileira Willi Bolle. Belo Horizonte: Editora UFMG; São Paulo: Imprensa Oficial do Estado de São Paulo, 2006.

BLANCHOT, Maurice, A conversa infinita; tradução Aurélio Guerra Neto, Escuta, São Paulo, 2001. 
BOLLE, Wille. Fisiognomia da metrópole moderna: representação da história em Walter Benjamin, Editora da Universidade de São Paulo, 2000.

DAMIÃO, Carla, Sobre o declínio da "sinceridade", filosofia e autobiografia de JeanJacques Rousseau a Walter Benjamin, Edições Loyola, São Paulo, 2006.

GAGNEBIN, Jeanne Marie. "Da escrita filosófica em Walter Benjamin". En: SELIGMANN-SILVA, Márcio, "Leituras de Walter Benjamin" (org), Fapesp: Annablume, São Paulo, 1999.

GAGNEBIN, Jeanne Marie, Lembrar escrever esquecer, Editora 34, São Paulo, 2006.

SARLO, Beatriz, Tiempo pasado, cultura de la memória y giro subjetivo. Ua discusión, Siglo XXI Editores Argentina, Buenos Aires, 2005.

YVANCOS, José Maria Pozuelos, De la autobiografia, Teorias y Estilos, Editorial Crítica, Barcelona, 2006.

\section{Notas}

${ }^{1}$ Brecht denominava essas conversas sem muita elaboração e refinamento teórico, mas com referência direta à realidade, de plumpes Denken, ou seja, "pensamento tosco". Mas é importante tentar acompanhar o neologismo criado pelo poeta, o verbo "mitahmen". Das "mitahmende" possui o substantivo Ahm, que diz respeito a uma antiga medida para líquidos, e o verbo "ahmen" significaria algo como medir um recipiente. Já Wohnen seria habitar. Nos verbos nachmachen/nachahmen, especificamente o prefixo "nach" significa "de acordo". "Nach-ahmen" significaria fazer exatamente como uma outra pessoa, tomando-a como referência, ou seja, imitando-a, copiando-a, seja na maneira de falar ou na eleição de um tema, de um motivo, ou até mesmo movimentos. Deve-se reter o sentido de um morar cujo formato é ajustado e obediente. Já mitahmende Wohnen significaria o contexto de morar "com" alguém, junto a.

${ }^{2}$ Para o tradutor português João Barrento, duas descobertas posteriores à publicação, em 1972, da Edição Crítica alemã da Obra Completa de Walter Benjamin devem ser examinadas e auxiliam no embaraço causado pelas sucessivas retomadas e transformações dos textos: a primeira, a análise do manuscrito dedicado a Stefan, filho de Benjamin, que fora escrito em 1932; a segunda, o datiloescrito, encontrado por Giorgio Agamben, em 1981, na Biblioteca Nacional de Paris. Conferir comentário 271-288. 